\title{
Defining 'healthy' in preschool-aged children for forced oscillation technique reference equations
}

\author{
Claire Shackleton, ${ }^{1}$ (i) Dorottya CZOVEK, ${ }^{1}$ Keith GRIMWOOD, ${ }^{2,3}$ Robert S. WARE, ${ }^{2}$ Bence RADiCS, ${ }^{4}$ \\ Zoltan HANTOS ${ }^{1,4}$ AND Peter D. SLY ${ }^{1}$
}

${ }^{1}$ Children's Lung Environment and Asthma Research, Child Health Research Centre, The University of Queensland, Brisbane, QLD; ${ }^{2}$ School of Medicine and Menzies Health Institute Queensland, Griffith University, Gold Coast, QLD; ${ }^{3}$ Departments of Infectious Diseases and Paediatrics, Gold Coast Health, Gold Coast, QLD, Australia; ${ }^{4}$ Department of Pulmonology, University of Szeged, Deszk, Hungary

\begin{abstract}
Background and objective: Selecting 'healthy' preschool-aged children for reference ranges may not be straightforward. Relaxing inclusion criteria for normative data does not affect spirometry $z$-scores. We therefore investigated the effect of similarly relaxing inclusion criteria in preschoolers on reference ranges for respiratory impedance (Zrs) using a modified forced oscillation technique (FOT).

Methods: The International Study of Asthma and Allergies in Childhood questionnaire classified 585 children into a healthy and five mutually exclusive groups. Zrs was measured between 4 and $26 \mathrm{~Hz}$ and resistance (R) and compliance (C) obtained by model fitting. Prediction models were determined using mixed effect models and z-scores compared between healthy children and the five groups.

Results: Zrs data were obtained for 494 participants (4.30 \pm 0.7 years) on 587 occasions. Comparison of the Zrs z-scores between the healthy children and the health groups found significant differences in children with asthma, current wheeze and respiratory symptoms, but not in children born preterm or with early-life wheeze. Adding these two groups to the healthy dataset had no significant effect on the distribution of $z$-scores and increased the size of the dataset by $22.3 \%$.

Conclusion: Our data suggest that preschool-aged children born preterm or with early-life wheeze can be included in FOT reference equations, while those with asthma, current wheeze and respiratory symptoms within 4 weeks of testing should be excluded. This more inclusive approach results in more robust FOT reference ranges.
\end{abstract}

Key words: forced oscillation technique, healthy subjects, reference values and preschool-aged, respiratory impedance.

Correspondence: Claire Shackleton, Children's Lung Environment and Asthma Research, Centre for Children's Health Research, L7, 62 Graham Street, South Brisbane, 4101 OLD, Australia. E-mail: c.shackleton@uq.edu.au

Received 23 April 2017; invited to revise 26 June 2017; revised 13 July 2017; accepted 28 August 2017 (Associate Editor: Stacey Peterson-Carmichael; Senior Editor: Paul King).

\section{SUMMARY AT A GLANCE}

Normative data for respiratory impedance (Zrs) measured with the forced oscillation technique in preschool-aged children use strict criteria to define healthy. Zrs z-scores in preterm-births and early-life wheezers did not differ from healthy children allowing a more inclusive approach for reference equations, without losing discriminative power for detecting lung disease.

Abbreviations: BIS, Barwon Infant Study; BPD, bronchopulmonary dysplasia; FOT, forced oscillation technique; ISAAC, International Study of Asthma and Allergies in Childhood; ORChID, Observational Research in Childhood Infectious Diseases; Rrs, respiratory resistance; Xrs, reactance; Zrs, respiratory impedance.

\section{INTRODUCTION}

The respiratory system undergoes significant growth and development during the preschool years. ${ }^{1}$ Being able to accurately and reliably measure these physiological changes would benefit the diagnosis, treatment and management of children with suspected or known respiratory disease. Emphasis should therefore not only be placed on the lung function measurement itself, but also on the establishment of reference equations used to define normal lung function. ${ }^{2}$ The unique challenges of measuring lung function during the preschool years were addressed previously by developing lung function tests and reference values specific to preschool-aged children. ${ }^{3}$ However, many of these lung function tests remain in the research setting and not employed routinely in clinical practice ${ }^{3,4}$ due, in part, to challenges in performing the test and interpreting the results.

The forced oscillation technique (FOT) is employed widely in the preschool population as a non-invasive measure of respiratory impedance $(\mathrm{Zrs})^{3-5}$ and there are several published reference equations specific to this age group. ${ }^{6-27}$ In general, reference equations are based on data from 'healthy' children, ideally obtained from an unbiased and representative sample of the 
population where the test is being administered. ${ }^{28}$ Whilst the participant characteristics for FOT reference equations are well-characterized, inconsistencies exist in exclusion criteria and the definition of 'healthy'. Children with an asthma diagnosis are excluded from most reference equations, ${ }^{8,10,11,14-16,18-27}$ while an asthma family history excluded children from six of these equations. ${ }^{8,14,15,18,19,21}$ Other inconsistencies in exclusion criteria include the time interval following a respiratory infection, ${ }^{8,10-16,18,19,21,22,24-26}$ a history of wheeze and preterm-birth. ${ }^{18,21,24-26}$ These inconsistencies in exclusion criteria (Table 1), between different reference equations highlight the challenges of defining and identifying 'healthy' preschool-aged children when developing reference equations.

So, how 'healthy' does a child have to be for inclusion in reference equations for lung function measurements? A previous study examined the influence of exclusion criteria on spirometry z-scores in children aged 5-11 years of age. ${ }^{30}$ It found that including children normally excluded from normative data (born preterm, low-birth weight, prior asthma or being mildly symptomatic at the time of measurement) did not substantially alter the overall z-scores for forced expiratory volume in $1 \mathrm{~s}\left(\mathrm{FEV}_{1}\right)$ and forced vital capacity (FVC). Adding these children who are typically excluded from 'healthy' reference equations increased the sample size by $25 \%$. This more inclusive approach to defining populations for establishing reference equations allows a more generalizable reference set, and is potentially more representative of patients in the clinical setting.

We therefore investigated whether preschool-aged children with: doctor-diagnosed asthma, early-life or current wheeze, preterm-birth or respiratory infection within 4 weeks of the study visit could be included in FOT reference equations developed for preschool-aged children without compromising the integrity of the equations. We also used the outputs from fitting a model to the Zrs spectrum to derive the resistive parameter $\mathrm{R}$, representing the frequency-independent Newtonian resistance and $\mathrm{C}$, characterizing compliance of the respiratory system during tidal breathing.

\section{METHODS}

Preschool children, aged 3-6 years from an urban setting were recruited from kindergartens in Brisbane, Australia and from community birth cohort studies; the Observational Research in Childhood Infectious Diseases study (ORChID), Brisbane, Australia ${ }^{31}$ and the Barwon Infant Study (BIS), Geelong, Australia. ${ }^{32}$ Children were also recruited from a local kindergarten in Szeged, Hungary. To optimize recruitment in kindergartens, parents of all attendees aged 3-6 years received recruitment packages (parent information sheet, consent form and a modified International Study of Asthma and Allergies (ISAAC) questionnaire ${ }^{33}$ ) and were asked to return the completed consent form and questionnaire before the study visit. The child's guardian was not required to be present at the study visit. The Children's Health Queensland (HREC/12/QRCH/ 23), The University of Queensland (2014000212), the Barwon Health (10/24) and the Hungarian Regional
(107/2015-SZTE) Human Ethics Committees approved the study.

\section{Clinical definitions}

Inclusion criteria for ORChID and BIS included: healthy at birth, without a major congenital abnormality or serious illness identified in the first days of life (BIS) and born at $>36$ weeks (ORChID) and $>33$ weeks (BIS) gestation. Whereas, all children aged 3-6 years from the kindergartens were eligible for recruitment, and children diagnosed with a chronic respiratory illness other than asthma, a congenital abnormality affecting their ability to stand or a disorder compromising lung development were excluded. 'Healthy' children fulfilled the following criteria: born term ( $\geq 37$ weeks gestation), free of any respiratory symptoms and no respiratory medication use within 4 weeks of the study visit, had never wheezed and no prior doctor-diagnosed asthma. Children who did not fit these criteria were classified into one of five groups; doctor-diagnosed asthma, current wheeze (wheeze episodes in the past and the last 12 months), early-life wheeze (wheeze episodes in the past, but not in the last 12 months), children born preterm ( $<37$ weeks gestation) and the respiratory symptom group (children with upper or lower respiratory infections within 4 weeks of the study visit). Classifications were determined from the modified ISAAC and were mutually exclusive with children assigned to the most abnormal; e.g. a child born preterm with current wheeze and an asthma diagnosis was included in the 'asthma' group.

\section{Measurements of Zrs}

Zrs was measured using custom made FOT equipment incorporating a wave-tube and a loudspeaker, ${ }^{34}$ in accordance with the American Thoracic Society/European Respiratory Society guidelines. ${ }^{3}$ Measurements were obtained using a pseudorandom signal between 4 and $26 \mathrm{~Hz}$. Children breathing tidally whilst wearing a nose-clip, had their cheeks firmly supported and a tight seal around an antibacterial mouthpiece (Bird Healthcare, Melbourne, Victoria, Australia). A minimum of three, 16-s artefact free and reproducible measurements were obtained and from these the Zrs spectra were ensemble averaged. A resistance (R)compliance (C)-inertance (I) model was fitted to the averaged Zrs spectra: $\mathrm{Zrs}=\mathrm{R}+\mathrm{j} \omega \mathrm{I}+(1 / \mathrm{j} \omega \mathrm{C})$, where $\mathrm{j}$ is the imaginary unit and $\omega$ is angular frequency; $\mathrm{R}$ was calculated between 10 and $20 \mathrm{~Hz}$ from the respiratory resistance (Rrs) data, while $\mathrm{C}$ and I were estimated between 6 and $26 \mathrm{~Hz}$ from the reactance (Xrs) data. ${ }^{35}$

\section{Statistical analysis}

Demographic and anthropometric data are presented as median and 25th-75th percentiles. Lung function variables were not normally distributed and all Xrs variables were transformed to absolute values. To achieve normality all Zrs variables underwent natural logarithmic-transformation prior to analysis. Differences in lung function between healthy children and children in other health groups were assessed using 
Table 1 Exclusion criteria for determining the selection of children included in reference equations for FOT adapted from Stanojevic ${ }^{29}$

\begin{tabular}{|c|c|c|c|c|}
\hline Reference & $\begin{array}{l}\text { Signal and } \\
\text { frequency }(\mathrm{Hz})\end{array}$ & $n$ & $\begin{array}{c}\text { Age } \\
\text { (years) }\end{array}$ & Exclusion criteria to define 'healthy' \\
\hline Williams et al. $(1979)^{7}$ & Pseudorandom $15-35 \mathrm{~Hz}$ & 16 & $3-5$ & Not stated. \\
\hline Morgan et al. $(1982)^{8}$ & Pseudorandom 2-15 Hz & 101 & $3-5$ & $\begin{array}{l}\text { Family or personal history of asthma, respiratory } \\
\text { symptoms at testing. }\end{array}$ \\
\hline Duiverman et al. $(1985)^{9}$ & Pseudorandom 2-26 Hz & 255 & $2-12$ & Wheeze (present and/or past), recurrent cough. \\
\hline Hantos et al. $(1985)^{10}$ & Pseudorandom 3-10 Hz & 121 & $4-16$ & $\begin{array}{l}\text { History of respiratory disease, acute respiratory } \\
\text { symptoms at testing. }\end{array}$ \\
\hline Hordvik et al. $(1985)^{11}$ & Pseudorandom 2-26 Hz & 138 & $2-16$ & $\begin{array}{l}\text { History of chronic or systemic disease affecting the } \\
\text { respiratory system, acute respiratory symptoms } \\
\text { (within 3-weeks of testing), more than incidental } \\
\text { smoke exposure. }\end{array}$ \\
\hline Solymar et al. $(1985)^{12}$ & $\begin{array}{l}\text { Single frequency } \\
2,4,12 \mathrm{~Hz}\end{array}$ & 218 & $2-18$ & $\begin{array}{l}\text { History of recurrent cough, wheeze, pneumonia, } \\
\text { cardiac disease, recent respiratory infection and } \\
\text { cigarette smoke exposure. }\end{array}$ \\
\hline Lierl and Hilman $(1986)^{13}$ & Pseudorandom 2-26 Hz & 90 & $4-7$ & $\begin{array}{l}\text { History of respiratory disease, respiratory symptoms } \\
\text { at testing. }\end{array}$ \\
\hline Lebecque et al. $(1991)^{14}$ & Single frequency $10 \mathrm{~Hz}$ & 377 & $3-18$ & $\begin{array}{l}\text { Prior history of wheeze or use of bronchodilators, } \\
\text { chronic cough, exercise intolerance, frequent or } \\
\text { severe upper respiratory tract infections URTI's, } \\
\text { use of cigarettes, major thoracic or cardiac } \\
\text { disorders, familial history of asthma, respiratory } \\
\text { symptoms within 4-weeks of testing. }\end{array}$ \\
\hline Ducharme et al. $(1998)^{15}$ & $\begin{array}{l}\text { Single frequency } \\
8,12,16 \mathrm{~Hz}\end{array}$ & 200 & $3-17$ & $\begin{array}{l}\text { Personal or family history of wheeze, asthma, } \\
\text { allergic rhinitis or dermatitis, low birth weight, } \\
\text { preterm-birth (<37-weeks), bronchopulmonary } \\
\text { dysplasia, neonatal ventilation, active or passive } \\
\text { smoke exposure, obesity, upper respiratory tract } \\
\text { infection, dyspnoea, cough, wheeze, } \mathrm{SpO}_{2}<95 \% \text {. }\end{array}$ \\
\hline Klug et al. $(1998)^{16}$ & Square-wave $5-35 \mathrm{~Hz}$ & 121 & $2-7$ & $\begin{array}{l}\text { Chronic disease, history of recurrent cough, wheeze, } \\
\text { severe pneumonia, eczema, atopic first degree } \\
\text { relatives, significant exposure to tobacco smoke } \\
\text { (>3 cigarettes a day), respiratory symptoms within } \\
\text { 4-weeks of testing. }\end{array}$ \\
\hline Hellinckx et al. $(1998)^{27}$ & $\begin{array}{l}\text { Impulse } \\
5-35 \mathrm{~Hz}\end{array}$ & 247 & $3-6$ & $\begin{array}{l}\text { A scoring system to define asthma that considered } \\
\text { history of wheeze, shortness of breath, cough, } \\
\text { asthma diagnosis and the use of respiratory } \\
\text { medications }\end{array}$ \\
\hline Frei et al. $(2005)^{18}$ & Impulse $5-35 \mathrm{~Hz}$ & 222 & $3-10$ & Same exclusion criteria as Ducharme et al. ${ }^{15}$ \\
\hline Dencker et al. $(2006)^{19}$ & Impulse $5-35 \mathrm{~Hz}$ & 360 & $2-11$ & $\begin{array}{l}\text { Past or present chronic respiratory disease, family } \\
\text { history of asthma, respiratory symptoms within 2- } \\
\text { weeks of testing. }\end{array}$ \\
\hline Hall et al. $(2007)^{20}$ & Pseudorandom 4-48 Hz & 158 & $2-7$ & $\begin{array}{l}\text { Doctor-diagnosed or parent reported respiratory } \\
\text { disease, asthma or wheeze (past or present), } \\
\text { parent reported cough in last 12-months. }\end{array}$ \\
\hline Nowowiejska et al. (2008) $)^{21}$ & Impulse $5-35 \mathrm{~Hz}$ & 626 & 3-19 & Same exclusion criteria as Ducharme et al. ${ }^{15}$ \\
\hline Vu et al. $(2008)^{22}$ & Single frequency $8 \mathrm{~Hz}$ & 175 & $6-11$ & $\begin{array}{l}\text { History (past and present) of wheeze, acute } \\
\text { respiratory symptoms at testing. }\end{array}$ \\
\hline Amra et al. $(2008)^{23}$ & Square-wave $5-25 \mathrm{~Hz}$ & 509 & $5-18$ & $\begin{array}{l}\text { Past or current history of respiratory disease } \\
\text { (including asthma), lifelong history of smoking } \\
100 \text { or more cigarettes }\end{array}$ \\
\hline Calogero et al. $(2010)^{25}$ & Pseudorandom 4-48 Hz & 163 & $2-6$ & $\begin{array}{l}\text { Preterm-birth ( }<36 \text {-weeks), supplemental } \mathrm{O}_{2} \text { after } \\
\text { birth for more than } 30 \text { days, doctor diagnosed } \\
\text { asthma, }>3 \text { wheeze episodes ever or wheeze in the } \\
\text { past } 12 \text {-months and free of respiratory symptoms } \\
\text { and sing at the time of testing. }\end{array}$ \\
\hline Calogero et al. $(2013)^{24}$ & Pseudorandom 4-48 Hz & 760 & $2-13$ & $\begin{array}{l}\text { Preterm-birth }\left(<36 \text {-weeks), supplemental } \mathrm{O}_{2} \text { at birth, }\right. \\
\text { doctor diagnosed-asthma, }>3 \text { wheeze episodes } \\
\text { ever or wheeze in the past } 12 \text {-months, respiratory } \\
\text { symptoms within } 3 \text {-weeks of testing }\end{array}$ \\
\hline
\end{tabular}


Table 1 Continued

\begin{tabular}{|c|c|c|c|c|}
\hline Reference & $\begin{array}{l}\text { Signal and } \\
\text { frequency }(\mathrm{Hz})\end{array}$ & $n$ & $\begin{array}{c}\text { Age } \\
\text { (years) }\end{array}$ & Exclusion criteria to define 'healthy' \\
\hline $\begin{array}{l}\text { Gochicoa-Rangel et al. } \\
(2015)^{26}\end{array}$ & Impulse $5-20 \mathrm{~Hz}$ & 283 & $2-15$ & $\begin{array}{l}\text { Presence of chronic illness including heart, liver } \\
\text { kidney and respiratory disease (asthma, wheezing } \\
\text { and rhinosinusitis). Past history of prematurity, } \\
\text { pneumonia, bronchiolitis and regular exposure to } \\
\text { environmental tobacco smoke or biomass smoke. } \\
\text { Absence of acute respiratory morbidity within } \\
15 \text { days of testing and without suspicion of sleep } \\
\text { apnoea/hypopnea or gastro-oesophageal reflux. }\end{array}$ \\
\hline
\end{tabular}

Age (years) presented as range.

$\mathrm{SpO}_{2}$, Oxygen saturation level as measured by pulse oximetry; URTI, Upper Respiratory Tract Infection.

Student's t-test. Normative equations were calculated using mixed-effects linear regression modelling. Mixedeffects models were used as data points from some children from the ORChID Study were included more than once. Initially, successive univarible models with height, weight, age and sex were included as the main effect were constructed. Then, multivariable models were built using combinations of main effects, before the most parsimonious multivariable model was selected using the likelihood ratio test. In all models, each child was included as a random effect, to account for the probable non-independence of observations from the same child. Z-scores were calculated using the equation: $\mathrm{Z}=$ (measured - predicted) $/ \mathrm{SD}$, where SD represents the overall standard deviation of the model. The influence of adding successively 'less healthy' children to the data set was determined by recalculating the regression equations and $\mathrm{z}$-scores and comparing the $\mathrm{z}$-scores between the newly defined healthy children and the children in other health groups to those obtained from the original equation.

\section{RESULTS}

A total of 494 children (mean age $4.30 \pm 0.68$ years) provided 587 analysable measurements of lung function; 31 children were measured twice; 28 measured three times and 2 children were measured four times, all on separate testing occasions. The overall feasibility percentage was $85.5 \%$ (670 testing occasions in total). Reasons for failure are detailed in Figure 1. Feasibility was marginally lower in children aged 3-4 years $(85.2 \%)$ than $5-6$ years of age $(88.1 \%)$.

Demographic and clinical characteristics of the health groups are summarized in Table 2, and lung function is shown in Table 3 for the common FOT outcome variables as well as for $\mathrm{R}$ and $\mathrm{C}$. The full range of Zrs variables are shown in Table S1 in Supplementary Information. Significant differences in lung function variables were detected between 'healthy' children and children with asthma (Rrs8 $P=0.044$ and Xrs10 $P=0.025)$, children born preterm (Xrs6 $P=0.011$ and
Figure 1 Participant flow through the study. FOT, forced oscillation technique; ISAAC, International Study of Asthma and Allergies.

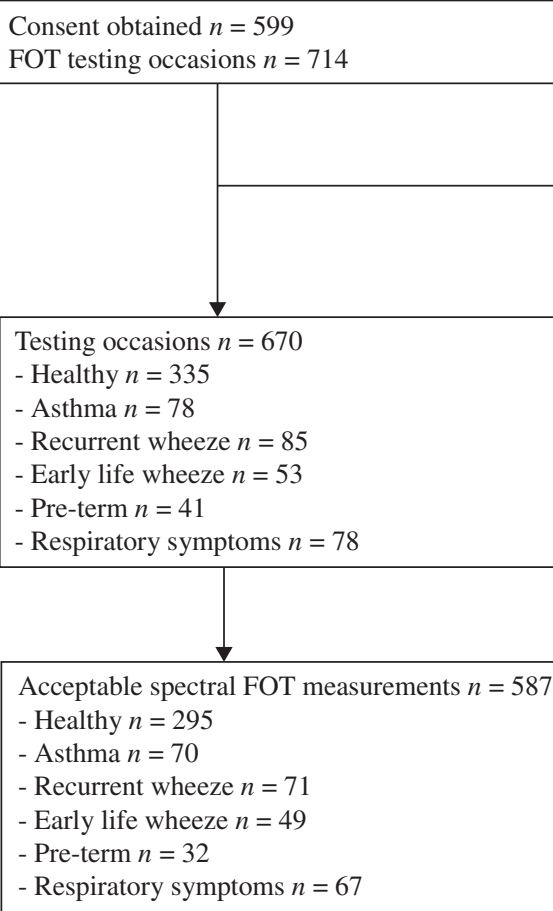


Table 2 Demographic and anthropomorphic characteristics of participants with acceptable and repeatable forced oscillation technique measurements

\begin{tabular}{lcccccc}
\hline & Healthy & Asthma & $\begin{array}{c}\text { Current } \\
\text { wheeze }\end{array}$ & $\begin{array}{c}\text { Early-life } \\
\text { wheeze }\end{array}$ & $\begin{array}{c}\text { Pre term birth } \\
\text { symptoms }\end{array}$ \\
\hline$n$ & 248 & 59 & 50 & 39 & 32 & 66 \\
$\begin{array}{l}\text { Gestational Age } \\
\text { (weeks) }\end{array}$ & $40(39 ; 40.6)$ & $39(38 ; 41)$ & $39.2(38 ; 40.4)$ & $40(39 ; 40.2)$ & $36.1(33.5 ; 37.0)$ & $40(39 ; 40.3)$ \\
Male $(n)$ & 126 & & & & & \\
Age (years) & $4.1(4.0 ; 4.7)$ & $4.2(4.0 ; 4.6)$ & $4.2(3.9 ; 4.7)$ & $4.5(3.9 ; 5.1)$ & $4.3(4.0 ; 4.8)$ & $4.3(3.9 ; 4.7)$ \\
Height $(\mathrm{cm})$ & 105.3 & 106.8 & 105.5 & $108.1 *$ & 103.08 & 105.5 \\
& $(102.0 ; 109.9)$ & $(102.8 ; 109.9)$ & $(101.4 ; 110.0)$ & $(103.0 ; 113.4)$ & $(99.8 ; 107.1)$ & $(101.0 ; 109.5)$ \\
Weight $(\mathrm{kg})$ & 17.2 & $17.8 *$ & 17.2 & $18.9 *$ & 16.6 & 17.5 \\
& $(15.8 ; 19.1)$ & $(16.1 ; 20.0)$ & $(16.0 ; 19.0)$ & $(16.5 ; 21.0)$ & $(15.2 ; 17.9)$ & $(16.1 ; 19.0)$ \\
\hline
\end{tabular}

Data presented as median $(25 ; 75 \%)$ in a study population in which $92 \%$ identify as Caucasian.

$* P<0.05$ compared to the healthy children. Preterm-birth (<37-weeks) and none diagnosed with bronchopulmonary dysplasia.

Xrs8 $P=0.038$ ), children with current wheeze (Xrs6 $P=0.046$, Xrs8 $P=0.013$ and $\mathrm{Xrs10} P=0.004)$ and in children with respiratory symptoms $(\mathrm{R} P=0.037$ and Rrs10 $P=0.046)$, with the major differences seen in the 6-10 Hz range (Table 3$)$.

For the traditional approach of defining 'healthy', all Zrs variables were significantly associated with height only $(P<0.001)$ (Table S2 in Supplementary Information). Z-scores calculated for each group using this analysis are shown for the commonly reported variables in Table 4. Compared to 'healthy' children, the asthmatic children had significantly different $\mathrm{z}$-scores at $\mathrm{R}(P=0.049), \operatorname{Rrs} 6(P=0.029)$, Rrs8 $(P=0.024)$, Rrs10 $(P=0.032), C(P=0.015), \operatorname{Xrs6}(P=0.047)$ and Xrs10 $(P=0.016)$. Whereas children classified as current wheezers were significantly different at Rrs6 $(P=0.031), \operatorname{Xrs8}(P=0.011)$ and $\operatorname{Xrs10}(P=0.013)$ and children with respiratory symptoms within 4 weeks of the FOT measurements had significantly different $\mathrm{z}$ scores at R $(P=0.014)$, Rrs8 $(P=0.012)$ and Rrs10 $(P=0.012)$.

The lack of significant differences in Zrs z-scores detailed in Table 4 between healthy children and children with early-life wheeze and those born preterm validated a more inclusive approach to defining healthy, increasing the healthy data set by 71 children. Prediction equations generated based on the newly defined healthy group are provided in Table S3 in Supplementary Information, and the relationship between $\mathrm{R}$ and $\mathrm{C}$ against height in Figure 2. Significant differences in the mean z-scores between the newly defined healthy children and children with asthma (R $(P=0.042), \operatorname{Rrs6}(P=0.024), \operatorname{Rrs} 8(P=0.016), \operatorname{Rrs} 10$ $(P=0.025), \mathrm{C}(P=0.035)$ and $\operatorname{Xrs10}(P=0.022))$, with

Table 3 Zrs variable for 6, 8 and $10 \mathrm{~Hz}$ for each of the health groups

\begin{tabular}{|c|c|c|c|c|c|c|}
\hline & Healthy & Asthma & Current wheeze & $\begin{array}{l}\text { Early-life } \\
\text { wheeze }\end{array}$ & Pre term birth & $\begin{array}{l}\text { Respiratory } \\
\text { symptoms }\end{array}$ \\
\hline$n$ & 248 & 59 & 50 & 39 & 32 & 66 \\
\hline $\mathrm{R}(\mathrm{hPa} \mathrm{s} / \mathrm{L})$ & $\begin{array}{c}8.27 \\
(7.25 ; 9.23)\end{array}$ & $\begin{array}{c}8.37 \\
(7.49 ; 9.81)\end{array}$ & $\begin{array}{c}8.52 \\
(7.57 ; 9.54)\end{array}$ & $\begin{array}{c}7.86 \\
(7.10 ; 9.00)\end{array}$ & $\begin{array}{c}8.53 \\
(7.63 ; 9.87)\end{array}$ & $\begin{array}{c}7.79 * \\
(6.77 ; 8.95)\end{array}$ \\
\hline Rrs6 (hPa s/L) & $\begin{array}{c}9.47 \\
(8.28 ; 10.61)\end{array}$ & $\begin{array}{c}9.71 \\
(8.94 ; 11.45)\end{array}$ & $\begin{array}{c}10.04 \\
(8.78 ; 11.68)\end{array}$ & $\begin{array}{c}9.63 \\
(7.99 ; 10.78)\end{array}$ & $\begin{array}{c}9.99 \\
(8.94 ; 11.04)\end{array}$ & $\begin{array}{c}9.00 \\
(7.61 ; 10.67)\end{array}$ \\
\hline Rrs8 (hPa s/L) & $\begin{array}{c}9.18 \\
(7.99 ; 10.27)\end{array}$ & $\begin{array}{c}9.57 * \\
(8.52 ; 10.90)\end{array}$ & $\begin{array}{c}9.56 \\
(8.41 ; 10.81)\end{array}$ & $\begin{array}{c}8.88 \\
(7.95 ; 9.98)\end{array}$ & $\begin{array}{c}9.05 \\
(8.50 ; 10.66)\end{array}$ & $\begin{array}{c}8.55 \\
(7.30 ; 9.93)\end{array}$ \\
\hline Rrs10 (hPa s/L) & $\begin{array}{c}8.76 \\
(7.82 ; 9.87)\end{array}$ & $\begin{array}{c}9.04 \\
(8.26 ; 10.48)\end{array}$ & $\begin{array}{c}9.13 \\
(8.22 ; 10.56)\end{array}$ & $\begin{array}{c}8.38 \\
(7.74 ; 9.80)\end{array}$ & $\begin{array}{c}8.84 \\
(8.02 ; 10.23)\end{array}$ & $\begin{array}{c}8.24^{*} \\
(7.22 ; 9.61)\end{array}$ \\
\hline $\mathrm{C}\left(\mathrm{hPa} \mathrm{s} \mathrm{mL} \mathrm{m}^{-1}\right)$ & $\begin{array}{c}8.03 \\
(6.59 ; 9.92)\end{array}$ & $\begin{array}{c}7.62 \\
(5.84 ; 8.98)\end{array}$ & $\begin{array}{c}7.81 \\
(5.91 ; 10.80)\end{array}$ & $\begin{array}{c}8.47 \\
(6.52 ; 10.76)\end{array}$ & $\begin{array}{c}7.57 \\
(4.95 ; 9.60)\end{array}$ & $\begin{array}{c}7.89 \\
(6.75 ; 10.55)\end{array}$ \\
\hline Xrs6 (hPa s/L) & $\begin{array}{c}-2.92 \\
(-3.70 ;-2.35)\end{array}$ & $\begin{array}{c}-3.21 \\
(-4.10 ;-2.46)\end{array}$ & $\begin{array}{c}-3.14 * \\
(-4.06 ;-2.51)\end{array}$ & $\begin{array}{c}-3.24 \\
(-3.73 ;-2.11)\end{array}$ & $\begin{array}{c}-3.21^{*} \\
(-4.70 ;-2.46)\end{array}$ & $\begin{array}{c}-2.83 \\
(-3.88 ;-2.30)\end{array}$ \\
\hline Xrs8 (hPa s/L) & $\begin{array}{c}-2.24 \\
(-2.88 ;-1.71)\end{array}$ & $\begin{array}{c}-2.46 \\
(-3.04 ;-1.83)\end{array}$ & $\begin{array}{c}-2.50 * \\
(-3.58 ;-1.89)\end{array}$ & $\begin{array}{c}-2.34 \\
(-3.20 ;-1.53)\end{array}$ & $\begin{array}{l}-2.62^{*} \\
(-3.86 ;-1.89)\end{array}$ & $\begin{array}{c}-2.20 \\
(-3.18 ;-1.59)\end{array}$ \\
\hline Xrs10 (hPa s/L) & $\begin{array}{c}-1.94 \\
(-2.60 ;-1.39)\end{array}$ & $\begin{array}{c}-2.25^{*} \\
(-2.98 ;-1.55)\end{array}$ & $\begin{array}{c}-2.22 * \\
(-3.33 ;-1.70)\end{array}$ & $\begin{array}{c}-1.96 \\
(-2.59 ;-1.20)\end{array}$ & $\begin{array}{c}-2.23 \\
(-3.41 ;-1.44)\end{array}$ & $\begin{array}{c}-1.87 \\
(-2.54 ;-1.10)\end{array}$ \\
\hline
\end{tabular}

Raw Zrs (Rrs and Xrs) data presented as median (25; 75\%). Preterm-birth (<37-weeks) and none diagnosed with bronchopulmonary dysplasia.

*Significant difference from healthy group, $P<0.05$.

C, compliance of the respiratory system; R, frequency-independent Newtonian resistance; Rrs, respiratory resistance; Xrs, reactance. 
Table 4 Mean (SD) z-scores calculated for each group using reference equations obtained using the conventional definition for healthy children

\begin{tabular}{|c|c|c|c|c|c|c|}
\hline & Healthy & Asthma & $\begin{array}{l}\text { Current } \\
\text { wheeze }\end{array}$ & $\begin{array}{l}\text { Early-life } \\
\text { wheeze }\end{array}$ & $\begin{array}{l}\text { Preterm- } \\
\text { birth }\end{array}$ & $\begin{array}{c}\text { Respiratory } \\
\text { symptoms }\end{array}$ \\
\hline$n$ & 294 & 70 & 71 & 49 & 32 & 67 \\
\hline $\mathrm{R}(\mathrm{hPa} \mathrm{s} / \mathrm{L})$ & $-0.01(1.00)$ & $0.25 *(1.02)$ & $0.15(0.92)$ & $-0.09(1.01)$ & $0.11(0.95)$ & $-0.35^{*}(1.10)$ \\
\hline Rrs6 (hPa s/L) & $-0.03(1.00)$ & $0.27 *(1.07)$ & $0.25 *(0.96)$ & $0.06(1.00)$ & $0.05(0.86)$ & $-0.30(1.14)$ \\
\hline Rrs8 (hPa s/L) & $-0.03(0.99)$ & $0.27 *(1.07)$ & $0.14(0.91)$ & $-0.10(0.96)$ & $0.03(0.92)$ & $-0.38 *(1.10)$ \\
\hline Rrs10 (hPa s/L) & $-0.02(0.99)$ & $0.27 *(1.06)$ & $0.19(0.96)$ & $-0.08(1.01)$ & $-0.02(0.92)$ & $-0.37 *(1.12)$ \\
\hline $\mathrm{C}\left(\mathrm{hPa} s \mathrm{~mL}^{-1}\right)$ & $0.03(1.00)$ & $-0.31 *(1.19)$ & $-0.21(1.21)$ & $0.06(1.01)$ & $-0.23(1.23)$ & $0.22(0.96)$ \\
\hline Xrs6 (hPa s/L) & $0.01(1.00)$ & $-0.26 *(1.38)$ & $-0.32(1.14)$ & $-0.01(1.01)$ & $-0.37(1.18)$ & $0.10(1.06)$ \\
\hline Xrs8 (hPa s/L) & $0.00(0.99)$ & $-0.22(1.17)$ & $-0.33 *(1.01)$ & $-0.04(1.06)$ & $-0.24(1.03)$ & $0.08(1.02)$ \\
\hline Xrs10 (hPa s/L) & $0.03(0.99)$ & $-0.30 *(1.03)$ & $-0.25^{*}(1.01)$ & $0.00(0.98)$ & $-0.05(1.23)$ & $0.29(0.96)$ \\
\hline
\end{tabular}

Preterm-birth (<37-weeks) and none diagnosed with bronchopulmonary dysplasia.

*Significantly different from healthy children $P<0.05$.

C, compliance of the respiratory system; R, frequency-independent Newtonian resistance; Rrs, respiratory resistance; Xrs, reactance.

current wheeze $(\operatorname{Rrs6}(P=0.031)$, Xrs8 $(P=0.021)$ and Xrs10 $(P=0.019))$ and children with respiratory symptoms within 4 weeks of the FOT measurements (Rrs6 $(P=0.041), \operatorname{Rrs} 8 \quad(P=0.009), \operatorname{Rrs} 10 \quad(P=0.009)$ and Xrs10 $(P=0.031)$ ) (Table S4 in Supplementary Information) were still significant after including children with early-life wheeze and children born preterm to the normative healthy data set.

\section{DISCUSSION}

A more inclusive approach to selecting children for developing FOT reference equations is possible without compromising test performance. This more inclusive approach to defining healthy preschool-aged children had no effect on the healthy group's FOT z-score distributions or on the ability to differentiate healthy children from children with asthma, current wheeze or those with respiratory symptoms within 4 weeks of FOT measurements. Combining the Zrs measurements of children with early-life wheeze and born preterm with the healthy children together to form a newly defined healthy normative group is more generalizable to the preschool-aged population in which FOT is being measured. Despite these children representing a small proportion of the study cohort, their inclusion to the normative data set increased the healthy population by $22.3 \%$, which to our knowledge makes this FOT reference set the largest published in Caucasian preschool-aged children.

Reference equations have typically applied strict criteria when defining a healthy population. But, as our study suggests this strict approach may not be required when establishing normative FOT reference data. Currently, published FOT reference equations ${ }^{9,12,14-16,18,20-22,24-26}$ excluded participants with a history of wheeze, whereas our data indicate that this is unnecessary in the preschool age range. This more inclusive approach is better reflective of the preschool population where wheeze with or without a viral illness is also commonly reported but has shown to be transient with minimal effects into older childhood. ${ }^{36}$ Data from the present study document that including children with wheeze in early-life, but without wheeze in the past 12-months does not adversely influence the reference equations. In many cross-sectional studies, especially in older children, parents may have forgotten mild episodes of wheeze in early-life. Our data suggest this does not matter. Children born preterm are another group often excluded from FOT normative data sets (Table 1). Studies undertaking FOT measurement's in children born preterm report reduced lung function compared to healthy children, which is independent of a history of bronchopulmonary dysplasia (BPD), ${ }^{3738-40}$ In the present study, lung function in 32 children born preterm (<37-weeks) was comparable to healthy children. The median $(25 ; 75 \%)$ gestational age of children born preterm in the present study was 36.1 (33.5; 37.0) weeks, whereas the studies reporting worse lung function in children with or without BPD were born at a much earlier gestation ( $<32$-weeks). Although the number of children born preterm in this study is small our data suggest that children born between 34 and 37weeks gestational age, should be included in normative FOT reference data, whereas children born very preterm ( $<32$-weeks) should not. Consideration is also given to respiratory symptoms when selecting healthy children for inclusion in reference ranges. Yet establishing an asymptomatic period in preschool-aged children can be difficult. Children attending childcare have increased exposure to other children and a greater risk of acute respiratory tract infections. ${ }^{31,41,42}$ Interestingly, in our cohort children with upper or lower respiratory infections had better lung function compared to healthy children. There are many possible explanations for this observation, all of which highlight the special requirements for collecting lung function data in the field in preschool-aged children. In this study, children were classified as having a respiratory infection if symptoms occurred within 4 weeks of the study visit. These data were obtained from a modified version of the ISAAC questionnaire administered before the study visit. Time between completing the ISAAC questionnaire and the study visit may have meant respiratory symptoms had subsided and medication used during 


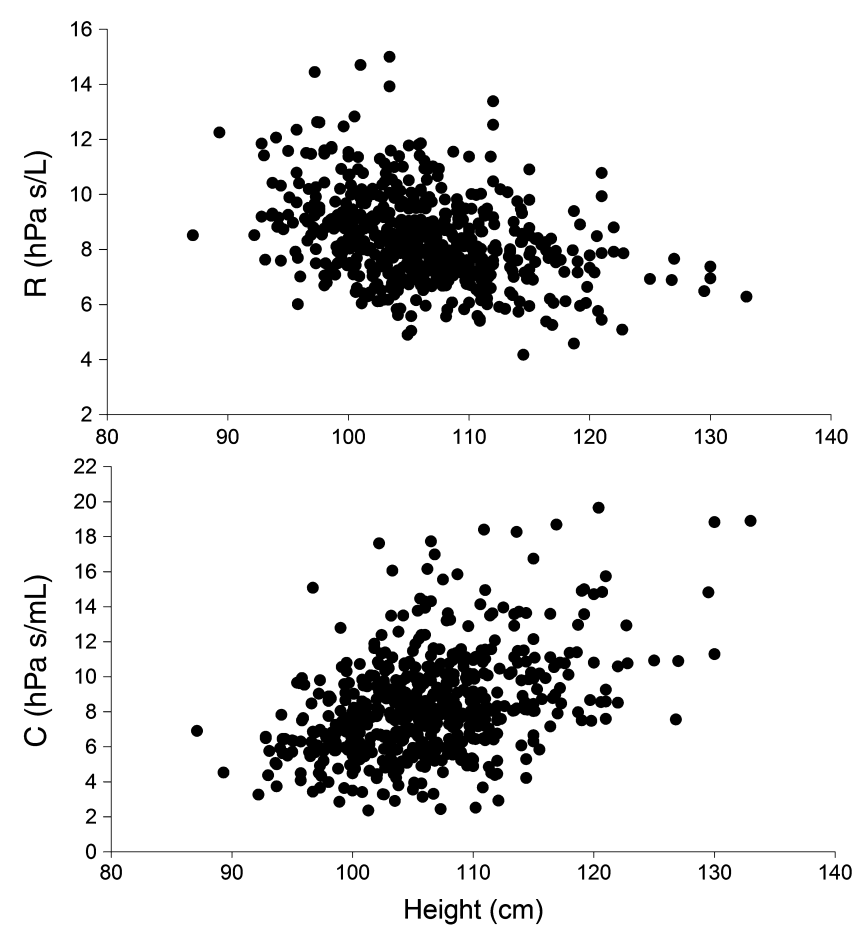

Figure 2 Resistance (R) and compliance (C) in healthy preschool aged children using a more inclusive approach to define healthy.

this symptomatic period might have improved lung function.

One of the factors limiting greater uptake of FOT in clinical practice may be the outcome variables reported. Clinicians have a concept of resistance, but the reporting of Rrs6, Rrs8 and Rrs10 begs the questions 'do they provide different information' and 'if not, why report three values?' Xrs as a concept is more challenging, especially as it has, by convention a negative value at low frequencies. Worse lung function is associated with more negative Xrs. In an attempt to make FOT more 'user friendly', we included a modelling approach to produce single values for $\mathrm{R}$ and $\mathrm{C}$, a concept more easily understood as $\mathrm{C}$ reflects the distensibility of the respiratory system. And although $\mathrm{C}$ is a robust parameter more easily understood than Xrs, it should be treated with caution in the presence of airway obstruction. When fitting the hyperbolic model for $\mathrm{C}$, the negative component of the Xrs curve is selected and is flatter in appearance compared to healthy controls, increasing the model fitting error. In the present study, there is essentially no difference in the clinical message from FOT, whether considering the traditionally reported single-frequency values of Rrs6, Rrs8, Rrs10, Xrs6, Xrs8, Xrs10 or the more comprehensive $\mathrm{R}$ and $\mathrm{C}$ derived from the simple resistance-compliance-inertance concept of respiratory mechanics. Accordingly, we have reported normative equations for both sets of data allowing comparisons to be made.

In summary, the data from the present study suggest a more inclusive and realistic approach can be taken to define a healthy population when developing FOT reference equations, without losing discriminate power for detecting lung disease.

\section{Acknowledgements}

The authors of this paper would like to acknowledge the contribution of staff from the Observational Research in Childhood Infectious Diseases study, the Early Life Lung Function study, the Barwon Infant Study and the Hungarian site for their contribution to data collection. We would also like to thank all the children and families who participated in these research studies. These studies have been supported by The National Health and Medical Research Council of Australia (\#1078600, \#1082307 and \#615700), the Hungarian Scientific Research Fund (\#105403) and the Australian Government Research Training Program Scholarship.

\section{Disclosure statement}

This study was previously presented at the annual conference of the European Respiratory Society in 2017.

P.D.S and Z.H. are named as inventors of a patent owned by Telethon Kids Institute Perth that covers volume dependence of lung function. The patent is licensed to Thorasys $P / L$, Montreal Canada, manufacturers of the tremoflo lung function testing equipment. Neither receive nor expect to receive royalties from Thorasys or Telethon Kids Institute.

\section{REFERENCES}

1 Lanteri CJ, Sly PD. Changes in respiratory mechanics with age. J. Appl. Physiol. 1993; 74: 369-78.

2 Crapo RO. The role of reference values in interpreting lung function tests. Eur. Respir. J. 2004; 24: 341-2.

3 Beydon N, Davis SD, Lombardi E, Allen JL, Arets HGM, Aurora P, Bisagaard H, Davis GM, Ducharme FM, Eigen H et al. An official American Thoracic Society/European Respiratory Society statement: pulmonary function testing in preschool children. Am. J. Respir. Crit. Care Med. 2007; 175: 1304-45.

4 Rosenfeld M, Allen J, Arets BH, Aurora P, Beydon N, Calogero C, Castile RG, Davis SD, Fuchs S, Gappa M et al. An official American Thoracic Society workshop report: optimal lung function tests for monitoring cystic fibrosis, bronchopulmonary dysplasia, and recurrent wheezing in children less than 6 years of age. Ann. Am. Thorac. Soc. 2013; 10: S1-s11.

5 Bates JHT, Irvin CG, Farre R, Hantos Z. Oscillation mechanics of the respiratory system. Compr. Physiol. 2011; 1: 1233-72.

6 Stanescu DC, Fesler R, Veriter C, Fans A, Brasseur LA. Modified measurement of respiratory resistance by forced oscillation during normal breathing. J. Appl. Physiol. 1975; 39: 305-11.

7 Williams SP, Fullton JM, Tsai MJ, Pimmel RL, Collier AM. Respiratory impedance and derived parameters in young children by forced random noise. J. Appl. Physiol. 1979; 47: 169-74.

8 Morgan WML, Wolf J, Souhrada JF. The measurement of total respiratory resistance in small children. J. Asthma 1982; 19: 233-40.

9 Duiverman EJ, Clement J, van de Woestijne KP, Neijens HJ, van den Bergh AC, Kerrebijn KF. Forced oscillation technique. Reference values for resistance and reactance over a frequency spectrum of 2-26 Hz in healthy children aged 2.3-12.5 years. Bull. Eur. Physiopathol. Respir. 1985; 21: 171-8.

10 Hantos Z, Daróczy B, Gyurkovits K. Total respiratory impedance in healthy children. Pediatr. Pulmonol. 1985; 1: 91-8.

11 Hordvik NL, König P, Morris DA, Kreutz C, Pimmel RL. Normal values for forced oscillatory respiratory resistance in children. Pediatr. Pulmonol. 1985; 1: 145-8.

12 Solymar L, Aronsson PH, Bake B, Bjure J. Respiratory resistance and impedance magnitude in healthy children aged 2-18 years. Pediatr. Pulmonol. 1985; 1: 134-40. 
13 Lierl MB, Hillman BC. Normal values for forced oscillation parameters in small children. J. Asthma 1986; 23: 179-85.

14 Lebecque P, Desmond K, Swartebroeckx Y, Dubois P, Lulling J, Coates A. Measurement of respiratory system resistance by forced oscillation in normal children: a comparison with spirometric values. Pediatr. Pulmonol. 1991; 10: 117-22.

15 Ducharme FM, Davis GM, Ducharme GR. Pediatric reference values for respiratory resistance measured by forced oscillation. Chest 1998; 113: 1322-8.

16 Klug B, Bisgaard H. Specific airway resistance, interrupter resistance, and respiratory impedance in healthy children aged 2-7 years. Pediatr. Pulmonol. 1998; 25: 322-31.

17 Hellinckx J, De Boeck K, Demedts M. No paradoxical bronchodilator response with forced oscillation technique in children with cystic fibrosis. Chest 1998; 113: 55-9.

18 Frei J, Jutla J, Kramer G, Hatzakis GE, Ducharme FM, Davis GM. Impulse oscillometry: reference values in children 100 to $150 \mathrm{~cm}$ in height and 3 to 10 years of age. Chest 2005; 128: 1266-73.

19 Dencker M, Malmberg LP, Valind S, Thorsson O, Karlsson MK, Pelkonen A, Pohjaupalo A, Haahtela T, Turpeinen M, Wollmer P. Reference values for respiratory system impedance by using impulse oscillometry in children aged 2-11 years. Clin. Physiol. Funct. Imaging 2006; 26: 247-50.

20 Hall GL, Sly PD, Fukushima T, Kusel MM, Franklin PJ, Horak F, Patterson H, Gangell C, Stick SM. Respiratory function in healthy young children using forced oscillations. Thorax 2007; 62: 521-6.

21 Nowowiejska B, Tomalak W, Radliński J, Siergiejko G, Latawiec W, Kaczmarski M. Transient reference values for impulse oscillometry for children aged 3-18 years. Pediatr. Pulmonol. 2008; 43: 1193-7.

22 LT V, Demoulin B, Nguyen MT, Nguyen YT, Marchal F. Respiratory impedance and response to salbutamol in asthmatic Vietnamese children. Pediatr. Pulmonol. 2010; 45: 380-6.

23 Amra BSF, Golshan M. Respiratory resistance by impulse oscillometry in healthy Iranian children aged 5-19 years. Iran. J. Allergy Asthma Immunol. 2008; 7: 25-9.

24 Calogero C, Simpson SJ, Lombardi E, Parri N, Cuomo B, Palumbo M, de Martino M, Shackleton C, Verheggen M, Gavidia T et al. Respiratory impedance and bronchodilator responsiveness in healthy children aged 2-13 years. Pediatr. Pulmonol. 2013; 48: 707-15.

25 Calogero C, Parri N, Baccini A, Cuomo B, Palumbo M, Novembre E, Morello P, Azzari C, de Martino M, Sly PD et al. Respiratory impedance and bronchodilator response in healthy Italian preschool children. Pediatr. Pulmonol. 2010; 45: 1086-94.

26 Gochicoa-Rangel L, Torre-Bouscoulet L, Martínez-Briseño D, Rodríguez-Moreno L, Cantú-González G, Vargas MH. Values of impulse oscillometry in healthy Mexican children and adolescents. Respir. Care 2015; 60: 119-27.

27 Hellinckx J, De Boeck K, Bande-Knops J, van der Poel M, Demedts M. Bronchodilator response in 3-6.5 years old healthy and stable asthmatic children. Eur. Respir. J. 1998; 12: 438-43.

28 Lung Function Testing. Selection of reference values and interpretative strategies. Am. Rev. Respir. Dis. 1991; 144: 1202-18.

29 Stanojevic S, Wade A, Lum S, Stocks J. Reference equations for pulmonary function tests in preschool children: a review. Pediatr. Pulmonol. 2007; 42: 962-72.

30 Lum S, Bountziouka V, Sonnappa S, Cole TJ, Bonner R, Stocks J. How "healthy" should children be when selecting reference samples for spirometry? Eur. Respir. J. 2015; 45: 1576-81.
31 Lambert SB, Ware RS, Cook AL, Maguire FA, Whiley DM, Bialasiewicz S, Mackay IM, Wang D, Sloots TP, Nissen MD et al. Observational Research in Childhood Infectious Diseases (ORChID): a dynamic birth cohort study. BMJ Open 2012; http:// doi.org/10.1136/bmjopen-2012-002134.

32 Vuillermin P, Saffery R, Allen KJ, Carlin JB, Tang MLK, Ranganathan $\mathrm{S}$ et al. Cohort profile: the Barwon Infant Study. Int. J. Epidemiol. 2015; 44: 1148-60.

33 Asher M, Keil U, Anderson H, Beasley R, Crane J, Martinez F, Mitchell EA, Pearce N, Sibbald B, Stewart AW et al. International Study of Asthma and Allergies in Childhood (ISAAC): rationale and methods. Eur. Respir. J. 1995; 8: 483-91.

34 Czövek D, Shackleton C, Hantos Z, Taylor K, Kumar A, Chacko A, Ware RS, Makan G, Radics B, Gingl Z et al. Tidal changes in respiratory resistance are sensitive indicators of airway obstruction in children. Thorax 2016; 71: 907-15.

35 Hantos Z, Czövek D, Gyurkovits Z, Szabó H, Maár BA, Radics B, Virag K, Makan G, Orvos H, Gingl Z et al. Assessment of respiratory mechanics with forced oscillations in healthy newborns. Pediatr. Pulmonol. 2015; 50: 344-52.

36 Martinez FD, Wright AL, Taussig LM, Holberg CJ, Halonen M, Morgan WJ et al. Asthma and wheezing in the first six years of life. N. Engl. J. Med. 1995; 332: 133-8.

37 Broström EB, Thunqvist P, Adenfelt G, Borling E, Katz-Salamon M. Obstructive lung disease in children with mild to severe BPD. Respir. Med. 2010; 104: 362-70.

38 Vrijlandt EJLE, Boezen HM, Gerritsen J, Stremmelaar EF, Duiverman EJ. Respiratory health in prematurely born preschool children with and without bronchopulmonary dysplasia. J. Pediatr. 2007; 150: 256-61.

39 Udomittipong K, Sly PD, Patterson HJ, Gangell CL, Stick SM, Hall GL. Forced oscillations in the clinical setting in young children with neonatal lung disease. Eur. Respir. J. 2008; 31: 1292-9.

40 Verheggen M, Wilson AC, Pillow JJ, Stick SM, Hall GL. Respiratory function and symptoms in young preterm children in the contemporary era. Pediatr. Pulmonol. 2016; 51: 1347-55.

41 Roberts L, Smith W, Jorm L, Patel M et al. Effect of infection control measures on the frequency of upper respiratory infection in child care: a randomized, controlled trial. Pediatrics 2000; 105: 738-42.

42 Sarna M, Ware RS, Sloots TP, Nissen MD, Grimwood K, Lambert SB. The burden of community-managed acute respiratory infections in the first 2-years of life. Pediatr. Pulmonol. 2016; 51: 1336-46.

\section{Supplementary Information}

Additional supplementary information can be accessed via the $\mathrm{htm} /$ version of this article at the publisher's website.

Table S1 Zrs variables by health status.

Table S2 Regression analyses based on the conventional approach to defining healthy.

Table S3 Regression analyses using the inclusive definition of healthy children.

Table S4 Mean (SD) z-scores calculated for each group using reference equations obtained based on the inclusive definition of healthy children to include those born preterm and those with early-life wheeze. 